\title{
IDENTIFIKASI PROFIL KUALITAS KOPI SEBAGAI ACUAN PENGEMBANGAN PRODUK SPESIALTI DI KAWASAN MENOREH, KULON PROGO, YOGYAKARTA
}

\author{
Coffee Quality Profile Identification as Product Development Guideline in Menoreh, \\ Kulon-Progo, Yogyakarta
}

\author{
Aldicky Faizal Amri, Ervika Rahayu Novita Herawati, Rifa Nurhayati, dan Agus Susanto \\ Balai Penelitian Teknologi Bahan Alam \\ Jalan. Jogja - Wonosari Km. 31.5, Yogyakarta, Indonesia \\ e-mail:aldifaiza10@gmail.com
}

\begin{abstract}
An understanding the characteristics of raw materials is important for the product development process. The characteristics and methods of processing of a coffee bean will affect its final quality and the taste of its brewed coffee. In Kulon-Progo Region, the coffee quality profile has not been identified clearly. Therefore, this research was conducted to identify the quality profile of coffee that grows in the Menoreh, Kulon Progo region so that it can be used as a guideline for further product development. Identification is carried out by testing the physical, chemical, and microbiological parameters and the taste of coffee grown in the Menoreh region, Kulon Progo. Physical, chemical and microbiological parameters testing is done by referring to SNI 1-3542-2004 concerning coffee powder. Taste testing is carried out with the help of expert panelists who refer to the SCAA Cupping Protocol. Based on this research results, the quality of Menoreh coffee has met the level I quality requirements of SNI 1-3542-2004 and has the potential to be developed into specialty coffee originating from the Special Region of Yogyakarta.
\end{abstract}

Keywords: Menoreh Coffee, Quality, Specialty Coffee, Product Development

\begin{abstract}
Abstrak: Pemahaman terhadap karakteristik bahan baku menjadi penting untuk proses pengembangan produk spesialti. Karakteristik dan proses pengolahan suatu biji kopi akan berpengaruh terhadap kualitas dan cita rasa hasil seduhan biji kopinya. Kopi yang tumbuh di wilayah Kulon Progo belum teridentifikasi profil kualitasnya dengan jelas. Maka dari itu, penelitian ini dilakukan untuk mengidentifikasi profil kualitas kopi yang tumbuh di wilayah Menoreh, Kulon Progo sehingga dapat dijadikan sebagai acuan pengembangan produk lebih lanjut. Identifikasi dilakukan dengan menguji parameter fisik, kimia, dan mikrobiologi serta cita rasa kopi yang tumbuh di wilayah Menoreh, Kulon Progo. Pengujian terhadap parameter fisik, kimia dan mikrobiologi dilakukan dengan mengacu pada SNI 1-3542-2004 tentang kopi bubuk. Pengujian cita rasa dilakukan dengan bantuan panelis ahli yang mengacu pada SCAA Cupping Protocol. Berdasarkan hasil penelitian ini, bahwa kopi Menoreh telah memenuhi persyaratan mutu tingkat I pada SNI 1-3542-2004 dan berpotensi untuk dikembangkan menjadi kopi specialty yang berasal dari Daerah Istimewa Yogyakarta.
\end{abstract}

Kata kunci: Kopi Menoreh, Kualitas, Kopi Specialty, Pengembangan Produk

\section{PENDAHULUAN}

Minuman dari biji kopi adalah salah satu produk yang paling populer dikonsumsi oleh berbagai kalangan. Secara komersil, jenis kopi yang paling banyak dikonsumsi adalah jenis kopi arabika (Coffea arabica) dan kopi robusta (Coffea canephora). Menurut Herrera dan Lambot (2017), sebanyak $67 \%$ spesies kopi di dunia dapat beradaptasi dan hidup pada ketinggian di bawah 1000 mdpl. Keberagaman jenis kopi menjadikannya suatu produk dengan kekayaan rasa yang unik. Karakter kualitas biji kopi berasal dari sifat genetik turunan khususnya karakter ukuran biji dan standar minuman yang diwakili oleh cita rasa, tingkat keasaman, dan body (Herrera dan Lambot, 2017). Kualitas cita rasa kopi bisa dipengaruhi oleh jenis biji, daerah tumbuh, dan proses budidayanya (Lambot et al., 2017). Selain itu, proses pengolahan pasca panen kopi dapat mengoptimalkan kualitas intrinsik suatu biji kopi (Sanz- 
Uribe et al., 2017). Aspek geografis, genetik, serta pengolahan berpadu dalam menciptakan karakteristik kualitas suatu biji kopi.

Pada pasar komoditas hasil pertanian, Indonesia adalah negara pengekspor komoditas hasil pertanian nomor delapan dengan sumbangsih $2,4 \%$ dari total ekspor komoditas hasil pertanian seluruh dunia pada tahun 2016. Berdasarkan data tersebut, Indonesia menjadi negara pengekspor komoditas hasil pertanian terbesar di kawasan Asia Tenggara (FAO, 2018). Pada komoditas kopi, saat ini Indonesia adalah penghasil biji kopi beras (green bean) terbesar keempat dibawah Brazil, Vietnam dan Kolombia dengan total produksi pada tahun 2017 sebesar 668.677 ton (FAO, 2019).

Akan tetapi dari sisi nilai ekspornya, Indonesia hanya berada pada peringkat 13 dunia dengan nilai 817,8 juta dolar AS. Indonesia bahkan tertinggal dari negara-negara seperti Honduras, Ethiopia, serta negaranegara dari Eropa yang memiliki angka total produksi biji kopi per tahun lebih rendah (Workman, 2019). Hal ini menandakan bahwa ekspor hasil komoditas kopi masih bernilai rendah di pasar dunia.

Salah satu sebab rendahnya nilai ekspor hasil komoditas kopi Indonesia adalah mutu dan tampilan produk kopi baik kopi biji dan kopi olahan yang rendah sehingga kalah bersaing dengan produk-produk dari negara lain (Kustiari, 2007).

Selain itu, komoditas kopi juga menghadapi permasalahan pada aspek ketidakstabilan pasar, kurangnya perhatian dari pemerintah terkait kebijakan pengembangan, produktivitas yang rendah baik dari sisi mutu dan kuantitas serta perubahan iklim (Sarirahayu, 2018).

Masalah yang dihadapi pada komoditas kopi Indonesia juga bersifat multi lini pada aspek bahan baku, produksi hingga pemasaran. Pada aspek bahan baku, rendahnya penanganan panen dan pasca panen oleh petani berimplikasi pada rendahnya mutu biji kopi yang dihasilkan. Pada aspek produksi, terbatasnya fasilitas produksi pengolahan kopi beserta penerapan Good Manufacturing Practices (GMP) yang rendah berimplikasi pada mutu produk yang dihasilkan rendah. Pada aspek pemasaran, rendahnya kemampuan berinovasi dan adopsi teknologi untuk melakukan diversifikasi produk kopi olahan menjadi proses pengembangan produk olahan kopi yang berdaya saing unggul terhambat (Sudjarmoko, 2013).

Sebagai solusi untuk permasalahan tersebut, potensi pengembangan komoditas kopi hasil rakyat harus dieksplorasi dengan memahami karakteristik jenis kopi yang digunakan sebagai bahan baku utamanya. Pemahaman tentang karakteristik jenis kopi diperlukan agar keunggulan kompetitif komoditas kopi dapat termanfaatkan (Aklimawati et al., 2014). Potensi tersebut menjadi penting untuk dieksplorasi karena permintaan produk kopi olahan cenderung mengalami kenaikan setiap tahun (Kustiari, 2007). Langkah pengembangan produk yang bermutu tinggi seperti specialty coffee juga diperlukan agar komoditas kopi Indonesia dapat tetap bersaing di pasar internasional (Hutabarat, 2004). Selain itu, aspek kualitas dari kopi Menoreh menjadi kekuatan yang potensial untuk diinformasikan sebagai "brand image" dalam proses promosi produk komoditas kopi (Sitanggang, 2013). Oleh karena itu, keunikan suatu jenis kopi perlu ditetapkan dalam standar agar proses pengendalian kualitas mutunya dapat direncanakan dengan tepat.

Salah satu jenis kopi yang dibudidayakan di Indonesia adalah kopi yang tumbuh di wilayah bukit Menoreh, Kabupaten Kulon Progo, Provinsi Daerah Istimewa Yogyakarta. Daerah penghasil utama komoditas kopi di Kabupaten Kulon Progo, Provinsi Daerah Istimewa Yogyakarta adalah Kecamatan Girimulyo dan Samigaluh yang terletak di wilayah perbukitan 
Menoreh. Kopi yang dihasilkan di wilayah tersebut diberi nama kopi Menoreh. Presentase hasil produksi kopi Menoreh di kecamatan Girimulyo dan Samigaluh pada tahun 2017 mencapai $84,29 \%$ dari total produksi di Kabupaten Kulon Progo (BPS, 2018). Kopi Menoreh tumbuh pada ketinggian 537 - 920 mdpl. Menurut (BPS, 2018), profil topografi dan iklim tempat tumbuhnya kopi Menoreh memiliki rata - rata curah hujan di Kabupaten Kulon Progo mencapai $248 \mathrm{~mm} /$ bulan dengan rata - rata jumlah hari hujan per bulan sebanyak 15 hari. Varian kopi yang tumbuh di Menoreh adalah varian jenis Arabika dan Robusta. Produk olahan yang dihasilkan dari varian jenis kopi Arabika dan Robusta dari kawasan bukit Menoreh adalah kopi bubuk. Tahapan proses pengolahannya dibagi menjadi 2 bagian yaitu proses pengolahan hulu dan proses pengolahan hilir. Proses pengolahan hulu adalah proses pengolahan yang bertujuan untuk menghasilkan biji kopi beras (green bean) (Yusianto dan Widyotomo, 2018). Proses pengolahan hulu dapat dibedakan menjadi 3 kategori umum, yaitu proses kering, proses basah dan semiwash (Yusianto dan Widyotomo, 2018). Biji kopi robusta dan arabika di Menoreh diolah dengan menggunakan proses semiwash. Setelah diperoleh green bean hasil proses semiwash, maka proses pengolahan hilir dilakukan.

Proses pengolahan hilir adalah proses pengolahan biji kopi beras (green bean) menjadi kopi bubuk siap seduh (Firmanto et al., 2018). Tahapan yang paling krusial pada proses pengolahan hilir adalah proses penyangraian (roasting). Proses ini dianggap paling krusial karena proses ini digunakan sebagai langkah pembentukan cita rasa kopi seduhan yang berdasarkan pada tingkat penyangraiannya (Schenker dan Rothgeb, 2017). Perbedaan tingkat penyangraian dapat berakibat pada penentuan metode seduh serta cita rasa seduhan kopi yang dihasilkan. Menurut Firmanto et al., (2018), tingkat sangrai yang umum dituju pada komoditas kopi di Indonesia adalah medium to dark. Tingkat sangrai medium to dark dapat dicapai dengan melakukan proses penyangraian pada tingkat suhu $205^{\circ} \mathrm{C}-225^{\circ} \mathrm{C}$. Tingkat sangrai tersebut diperoleh dengan cara menghentikan proses penyangraian pada waktu antara akhir bunyi letupan (crack) biji kopi pertama dengan crack kedua (Firmanto et al., 2018). Dalam proses pengolahan hilir yang telah dilakukan oleh produsen kopi Menoreh di Kulon Progo sudah dihasilkan kopi dengan tingkat sangrai medium to dark. Kopi bubuk siap seduh dihasilkan dari proses penghalusan biji kopi sangrai dengan menggunakan mesin penggiling (grinder). Mesin yang digunakan oleh pihak kelompok tani produsen kopi Menoreh adalah mesin grinder yang diberi saringan sebesar 1 $\mathrm{mm}$. Melalui proses penggilingan tersebut maka diperoleh kopi bubuk dengan ukuran medium. Kopi bubuk tersebut akan langsung dikemas untuk bisa diperdagangkan.

Selain untuk meningkatkan nilai tambah produk, proses pengolahan hilir kopi juga perlu dikendalikan agar kualitas produk akhirnya dapat terjamin dengan baik. Hingga saat ini, informasi mengenai kualitas kopi Menoreh, Kulon Progo, belum dapat didefinisikan dengan jelas. Penelitian ini bertujuan untuk mengetahui profil kualitas dan cita rasa kopi Menoreh sehingga dapat diperoleh definisi jelas mengenai karakter kopi Menoreh, Kulon Progo, Daerah Istimewa Yogyakarta. Dalam mencapai tujuan tersebut, maka perlu dilakukan identifikasi terhadap kualitas kopi Menoreh berdasarkan parameter kimia, fisik, mikrobiologi dan cita rasanya. Berdasarkan identifikasi tersebut maka dapat disusun profil cita rasa kopi Menoreh sehingga proses pengendalian kualitas mutunya dapat direncanakan dengan tepat serta saran untuk pengembangan produk olahan yang berasal dari biji kopi Menoreh menjadi lebih fokus. 


\section{METODE PENELITIAN}

Pada penelitian ini dilakukan pengujian untuk parameter fisik, kimia, mikrobiologi dan cita rasa pada biji kopi yang berasal dari Bukit Menoreh, Kulon Progo. Sebagai tambahan, data - data pendukung diperoleh melalui sumber sekunder dan observasi pada Kelompok Tani Madigondo yang menjadi mitra pada penelitian ini. Data pendukung yang diperlukan adalah profil wilayah pertumbuhan tanaman kopi, dan profil proses produksi olahan kopi yang dilakukan oleh mitra penelitian. Sampel biji dan kopi bubuk Menoreh diperoleh dari kelompok tani Madigondo, Kabupaten Kulon Progo, Provinsi Daerah Istimewa Yogyakarta. Sampel biji dan kopi bubuk diambil secara acak sebanyak 500 gram untuk tiap varian kopi robusta Menoreh dan arabika Menoreh. Kedua varian biji kopi Menoreh tersebut telah diolah dengan menggunakan proses semiwash.

Tahapan pengolahan hulu biji kopi dengan proses semiwash tersebut dapat dilihat pada Gambar 1.

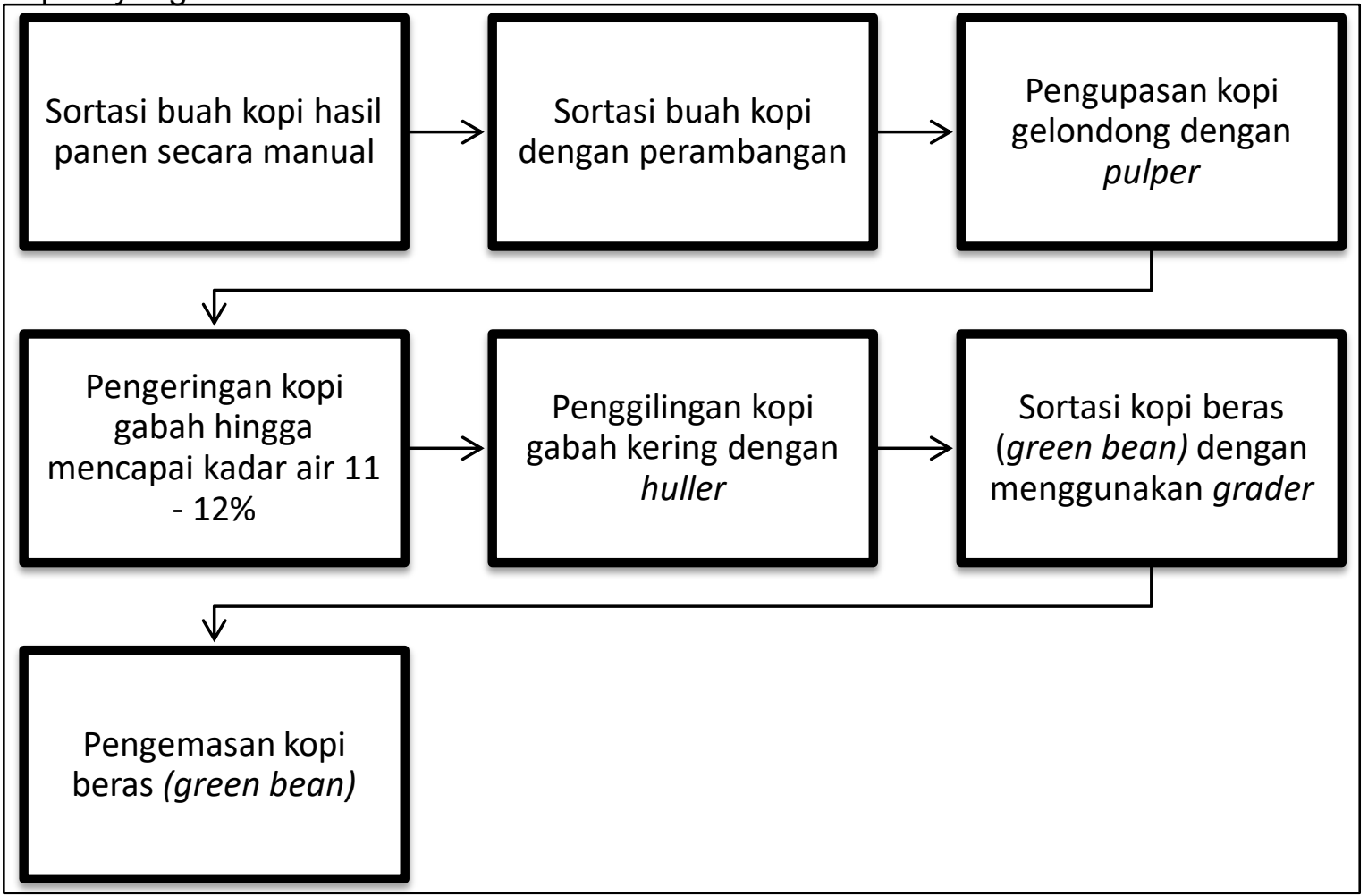

Gambar 1. Proses pengolahan hulu kopi Menoreh dengan semiwash

Green bean kopi Menoreh yang telah diperoleh dari proses semiwash akan dijadikan bubuk dengan menggunakan proses pengolahan hilir yang dapat dilihat tahapannya pada Gambar 2. Green bean tersebut juga digunakan sebagai sampel untuk pengujian cita rasa.

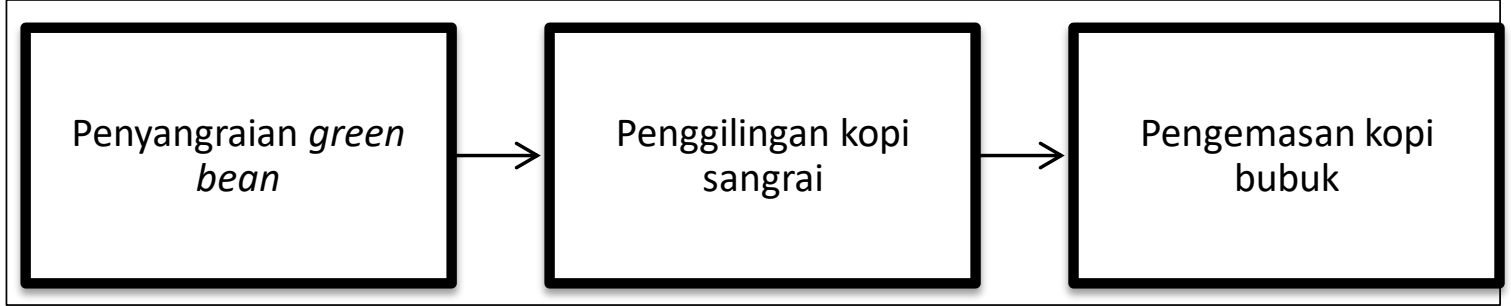

Gambar 2. Proses pengolahan hilir kopi Menoreh 
Kopi bubuk hasil proses pengolahan hilir green bean kopi Menoreh digunakan sebagai sampel untuk diuji parameter fisik, kimia, dan mikrobiologinya. Pengujian untuk parameter fisik, kimia dan mikrobiologi dilakukan dengan mengacu pada Standar Nasional Indonesia (SNI) 13542-2004 untuk kopi bubuk (BSN, 2004). Pengujian itu dilakukan di Balai Besar Industri Agro, Bogor. Jumlah sampel yang diujikan adalah 500 gram kopi bubuk untuk masing-masing varian arabika dan robusta. Tingkat pemenuhan kualitas produk terhadap persyaratan mutu pada standar kualitasnya diperoleh dengan melakukan perbandingan antara nilai hasil uji parameter dengan nilai persyaratan mutu parameternya. Pengujian parameter berdasarkan suatu standar kualitas skala nasional pada suatu produk diperlukan untuk mengetahui tingkat kesesuaian kualitas suatu produk terhadap persyaratan mutu yang telah ditetapkan pada standar kualitasnya. Kualitas produk yang memenuhi persyaratan mutu pada standar kualitasnya menandakan bahwa produk tersebut memiliki nilai tambah dibandingkan dengan produk yang tidak memenuhi persyaratan mutunya (BSN, 2013).

Pengujian cita rasa dilakukan dengan menggunakan bantuan panelis ahli dari Pusat Penelitian Kopi dan Kakao, Jember untuk mengetahui komponen cita rasa utamanya. Sampel yang digunakan dalam pengujian ini adalah biji kopi arabika dan robusta Menoreh. Pengujian cita rasa ini mengikuti kaidah Specialty Coffee Association of America (SCAA) Cupping Protocol yang telah dianggap secara skala global sebagai metode penilaian cita rasa suatu minuman kopi (Lingle dan Menon, 2017). SCAA Cupping Protocol merupakan standar pengujian cita rasa yang telah disusun untuk menilai kualitas atribut kopi secara objektif dan sebisa mungkin disesuaikan dengan kemampuan panca indera manusia (Lingle dan Menon, 2017). Berdasarkan standar pengujian tersebut, maka terdapat 10 atribut kualitas yang harus dinilai dari setiap jenis kopi yang diujikan. Pada varian kopi arabika 10 atribut kualitas tersebut adalah (1) fragrance/aroma; (2) flavor; (3) aftertaste; (4) acidity; (5) body; (6) uniformity; (7) balance; (8) clean cup; (9) sweetness; dan (10) overall. Pada varian kopi robusta 10 attribut kualitas tersebut adalah (1) fragrance/aroma; (2) flavor, (3) aftertaste; (4) bitter/sweet aspect ratio; (5) mouthfeel/body; (6) balance; (7) salt/acid aspect ratio; (8) uniform cups; (9) clean cups; dan (10) overall. Pengujian cita rasa dilakukan oleh panelis ahli dengan memberikan penilaian terhadap masing-masing atribut kualitas kopi. Rentang penilaian untuk tiap atribut kualitas adalah 1-10 dimana nilai total untuk pengujian cita rasa adalah hasil dari penambahan nilai masing-masing atribut kualitasnya. Sampel dikirimkan dalam bentuk biji kopi beras (green bean). Jumlah sampel yang diujikan adalah 500 gram untuk masing-masing varian arabika dan robusta.

Melalui hasil pengujian tersebut maka akan diperoleh profil kualitas Kopi Menoreh yang didasarkan pada kesesuain kualitas kopi Menoreh dengan persyaratan mutu dalam standar kualitas skala nasional yang berlaku beserta komponen cita rasa utama yang teridentifikasi berdasarkan panelis ahli.

\section{HASIL DAN PEMBAHASAN}

Berdasarkan hasil pengujian fisik, kimia dan mikrobiologi terhadap kopi bubuk arabika dan robusta Menoreh yang telah dilakukan maka diperoleh hasil pada tabel 1 dan tabel 2. 
Jurnal Industri Hasil Perkebunan Vol. 15 No. 1, Juni 2020: 17-28

Tabel 1. Hasil uji kopi bubuk Arabika Menoreh, Kulon Progo

\begin{tabular}{|c|c|c|c|c|}
\hline Parameter & Satuan & Persyaratan I & Persyaratan II & Hasil Uji \\
\hline Sari kopi & $\%$ & $20-36$ & maks. 60 & 23 \\
\hline Kealkalian abu & $\underset{\text { gram }}{\operatorname{ml}} \mathrm{N} N \mathrm{NaOH} / 100$ & $57-64$ & $\min .35$ & 61,9 \\
\hline
\end{tabular}

Cemaran Logam

\begin{tabular}{lllll} 
Timbal $(\mathbf{P b})$ & $\mathrm{mg} / \mathrm{kg}$ & maks. 2,0 & maks. 2,0 & $<0,034$ \\
Tembaga (Cu) & $\mathrm{mg} / \mathrm{kg}$ & maks. 30,0 & maks. 30,0 & 11,5 \\
Seng $(\mathbf{Z n})$ & $\mathrm{mg} / \mathrm{kg}$ & maks. 40,0 & maks. 40,0 & 4,56 \\
Raksa $(\mathbf{H g})$ & $\mathrm{mg} / \mathrm{kg}$ & maks. 0,03 & maks. 0,03 & $<0,005$ \\
Arsen (As) & $\mathrm{mg} / \mathrm{kg}$ & maks. 1,0 & maks. 1,0 & $<0,013$ \\
\hline $\begin{array}{l}\text { Cemaran Mikroba } \\
\text { Angka Lempeng }\end{array}$ & koloni/gram & maks. 10^6 & maks. 10^6 & $1,1 \times 10^{\wedge} 2$ \\
$\begin{array}{l}\text { Total 30C, 72 jam } \\
\text { Kapang }\end{array}$ & & & & \\
\hline
\end{tabular}

\begin{tabular}{lllll}
\multicolumn{6}{c}{ Tabel 2. Hasil uji kopi bubuk Robusta Menoreh, Kulon Progo } \\
\hline Parameter & Satuan & Persyaratan I & Persyaratan II & Hasil Uji \\
\hline Sari kopi & $\%$ & $20-36$ & maks. 60 & 25,3 \\
Kealkalian abu & ml N NaOH/100 & $57-64$ & min. 35 & 60,3 \\
& gram & & &
\end{tabular}

Cemaran Logam

\begin{tabular}{|c|c|c|c|c|}
\hline Timbal (Pb) & $\mathrm{mg} / \mathrm{kg}$ & maks. 2,0 & maks. 2,0 & $<0,034$ \\
\hline Tembaga (Cu) & $\mathrm{mg} / \mathrm{kg}$ & maks. 30,0 & maks. 30,0 & 19,6 \\
\hline Seng (Zn) & $\mathrm{mg} / \mathrm{kg}$ & maks. 40,0 & maks. 40,0 & 5,28 \\
\hline Raksa (Hg) & $\mathrm{mg} / \mathrm{kg}$ & maks. 0,03 & maks. 0,03 & $<0,005$ \\
\hline Arsen (As) & $\mathrm{mg} / \mathrm{kg}$ & maks. 1,0 & maks. 1,0 & $<0,013$ \\
\hline \multicolumn{5}{|l|}{ Cemaran Mikroba } \\
\hline $\begin{array}{l}\text { Angka Lempeng } \\
\text { Total } 30 \mathrm{C}, 72 \text { jam }\end{array}$ & koloni/gram & maks. $10^{\wedge} 6$ & maks. $10^{\wedge} 6$ & $7,3 \times 10^{\wedge} 2$ \\
\hline Kapang & koloni/gram & maks. $10^{\wedge} 4$ & maks. $10^{\wedge} 4$ & $1,8 \times 10^{\wedge} 2$ \\
\hline
\end{tabular}

Parameter yang digunakan dalam syarat mutu kopi bubuk adalah sari kopi dan kealkalian abu. Parameter tersebut dijadikan sebagai syarat mutu pada kopi bubuk karena menunjukkan jumlah zat terlarut dalam air selama proses penyeduhan dan tingkat kandungan mineral pada suatu kopi. Mutu kopi yang baik akan lebih bersih sehingga kandungan mineralnya tinggi yang berakibat pada kadar abu yang dihasilkan juga akan semakin tinggi 
(Edvan et al., 2016). Hasil uji parameter sari kopi beserta kealkalian abu dari kopi arabika Menoreh dan kopi robusta Menoreh adalah 23; 61,9 dan 25,3; 60,3 . Berdasarkan hasil uji tersebut, menunjukkan bahwa kadar sari kopi arabika Menoreh lebih rendah dibandingkan dengan kadar sari kopi robusta Menoreh. Dari perbandingan itu juga dapat dinyatakan bahwa kadar jumlah zat terlarut dari kopi arabika Menoreh lebih rendah dibandingkan dengan kopi robusta Menoreh. Hal tersebut sudah sesuai dengan pernyataan Suwarmini, (2017) bahwa kadar sari kopi arabika bernilai lebih rendah dibandingkan dengan kadar sari kopi robusta. Hasil uji sari kopi pada kopi arabika dan robusta Menoreh juga telah memenuhi persyaratan mutu I dari SNI 1-3542-2004. Kealkalian abu adalah suatu ukuran untuk menyatakan keberadaan kombinasi kation dan asam organik pada suatu bahan. (Sancho et al., 1992, Heidger, 2015). Pada hasil uji parameter kealkalian abu, nilai kealkalian abu kopi arabika Menoreh lebih tinggi dibandingkan kopi robusta Menoreh. Perbandingan tersebut menunjukkan bahwa mutu kopi arabika Menoreh lebih baik daripada mutu kopi robusta Menoreh karena kopi arabika Menoreh memiliki tingkat kandungan kombinasi kation dengan asam organik yang lebih tinggi dibandingkan kopi robusta Menoreh. Hasil uji kealkalian abu pada kopi arabika dan robusta Menoreh juga telah memenuhi persyaratan mutu I dari SNI 1-35422004. Berdasarkan hasil uji parameter fisik pada kedua varian kopi Menoreh, maka kopi arabika dan robusta Menoreh dinyatakan memenuhi persyaratan mutu tingkat I pada SNI 13542-2004.

Cemaran logam berat terhadap produk dijadikan sebagai parameter syarat mutu kopi bubuk. Pengujian terhadap cemaran logam berat diperlukan sebagai upaya meningkatkan keamanan produk pangan (BSN, 2009). Hal ini dikarenakan logam berat yang masuk ke dalam tubuh manusia melalui produk pangan tidak dapat diurai oleh tubuh sehingga dapat menyebabkan gangguan kesehatan jika terakumulasi hingga mencapai jumlah tertentu (Efanny, 2018). Salah satu mekanisme kontaminasi logam berat pada produk pangan adalah melalui peralatan produksi yang digunakan. Menurut Pragita et al., (2017), penggunaan alat produksi yang tidak menggunakan bahan food grade dapat berpengaruh terhadap jumlah kandungan cemaran logam berat pada produk tempe sehingga melebihi dari persyaratan mutu yang telah ditetapkan. Mekanisme kontaminasi logam juga dapat terjadi pada proses pengolahan hilir kopi Menoreh. Hal itu dapat disebabkan oleh kontak langsung antara permukaan bahan baku (green bean) dengan permukaan alat proses produksi kopi bubuk seperti roaster, grinder dan sealer yang berbahan dasar logam. Cemaran logam berat pada bahan pangan juga dapat diakibatkan oleh kondisi geologi tanah dimana tanaman dibudidayakan dan kondisi air yang digunakan dalam proses penyiraman tanaman (Widaningrum, 2007). Cemaran logam berat yang diujikan pada kopi bubuk Menoreh adalah Timbal (Pb), Tembaga $(\mathrm{Cu})$, Seng ( $\mathrm{Zn})$, Raksa ( $\mathrm{Hg})$, dan Arsen (As). Hasil uji yang diperoleh pada kopi bubuk dari varian arabika Menoreh terhadap cemaran logam $\mathrm{Pb}, \mathrm{Cu}, \mathrm{Zn}$, $\mathrm{Hg}$, dan As secara berurutan adalah < 0,034; 11,5; 4,56; < 0,005 dan <0,013. Hasil uji yang diperoleh pada kopi bubuk dari varian robusta Menoreh terhadap cemaran logam $\mathrm{Pb}, \mathrm{Cu}, \mathrm{Zn}$, $\mathrm{Hg}$, dan As secara berurutan adalah < 0,034; 19,6; 5,28; < 0,005 dan < 0,013. Berdasarkan hasil uji parameter cemaran logam berat pada kedua varian kopi Menoreh, maka kopi arabika dan robusta Menoreh dinyatakan memenuhi persyaratan mutu tingkat I pada SNI 1-3542-2004.

Cemaran mikroba terhadap produk dijadikan parameter syarat mutu kopi bubuk. Hal ini dikarenakan pengujian cemaran mikroba merupakan bagian dari sistem manajemen mutu 
dan keamanan pangan yang bertujuan untuk meningkatkan keyakinan terhadap keamanan suatu produk pangan (Martoyo et al., 2014). Sama halnya pada bubuk coklat, kopi bubuk yang digunakan sebagai bahan baku utama dalam produk minuman kopi memerlukan pengujian cemaran mikroba sebagai langkah validasi keamanan produknya (Ariyanti dan Suprapti, 2016). Paramater tersebut dinyatakan dengan menghitung nilai Angka Lempeng Total (ALT) pada suhu $30^{\circ} \mathrm{C}$ dalam rentang waktu 72 jam dan jumlah Kapang. Hasil uji nilai ALT dan jumlah kapang pada varian kopi arabika Menoreh adalah 1,1 x 10^2 dan 1,3 x 10^2. Hasil uji nilai ALT dan jumlah kapang pada varian kopi robusta Menoreh adalah $7,3 \times 10^{\wedge} 2$ dan $1,8 \times$ $10^{\wedge} 2$. Berdasarkan hasil uji parameter cemaran mikrobia pada kedua varian kopi Menoreh, maka kopi Menoreh dinyatakan memenuhi persyaratan mutu tingkat I pada SNI 1-3542-2004.

Berdasarkan hasil uji yang ditampilkan pada tabel 1 dan 2, kualitas kopi bubuk arabika dan robusta Menoreh sudah memenuhi persyaratan SNI 1-3542-2004. Hal ini dibuktikan dengan nilai dari seluruh parameter mutu kopi bubuk arabika dan robusta Menoreh yang telah memenuhi persyaratan I pada SNI 1-3542-2004.
Nilai parameter yang telah memenuhi syarat 1 menandakan bahwa proses pengolahan kopi bubuk yang telah dilakukan oleh Kelompok Tani Madigondo, Kulon Progo memenuhi standar mutu kopi bubuk tingkat nasional.

Pengujian cita rasa dilakukan oleh panelis ahli yang mengacu pada SCAA Cupping Protocol telah dilakukan. Hasil uji cita rasa tersebut juga dilengkapi oleh catatan dari panelis ahli yang ditunjukkan dengan kata-kata yang terdapat pada Specialty Coffee Association (SCA) Coffee Taster's Flavor Wheel. SCA Coffee Taster's Flavour Wheel adalah sebuah alat bantu untuk menguji cita rasa kopi dan berguna sebagai sumber informasi yang akurat untuk menggambarkan cita rasa kopi. SCA Coffee Taster's Flavour Wheel telah dikembangkan oleh kolaborasi antara SCA dan World Coffee Research (WCR) sejak 1995 (SCA, 2019). Kata - kata yang terdapat di dalam SCA Coffee Taster's Flavour Wheel digunakan untuk memahami dan memberikan tanda pada cita rasa khas dari kopi yang terdeteksi secara sensoris oleh para panelis ahli (WCR, 2017). Hasil dari pengujian cita rasa kopi Menoreh dapat dilihat pada Gambar 3 sebagai berikut :

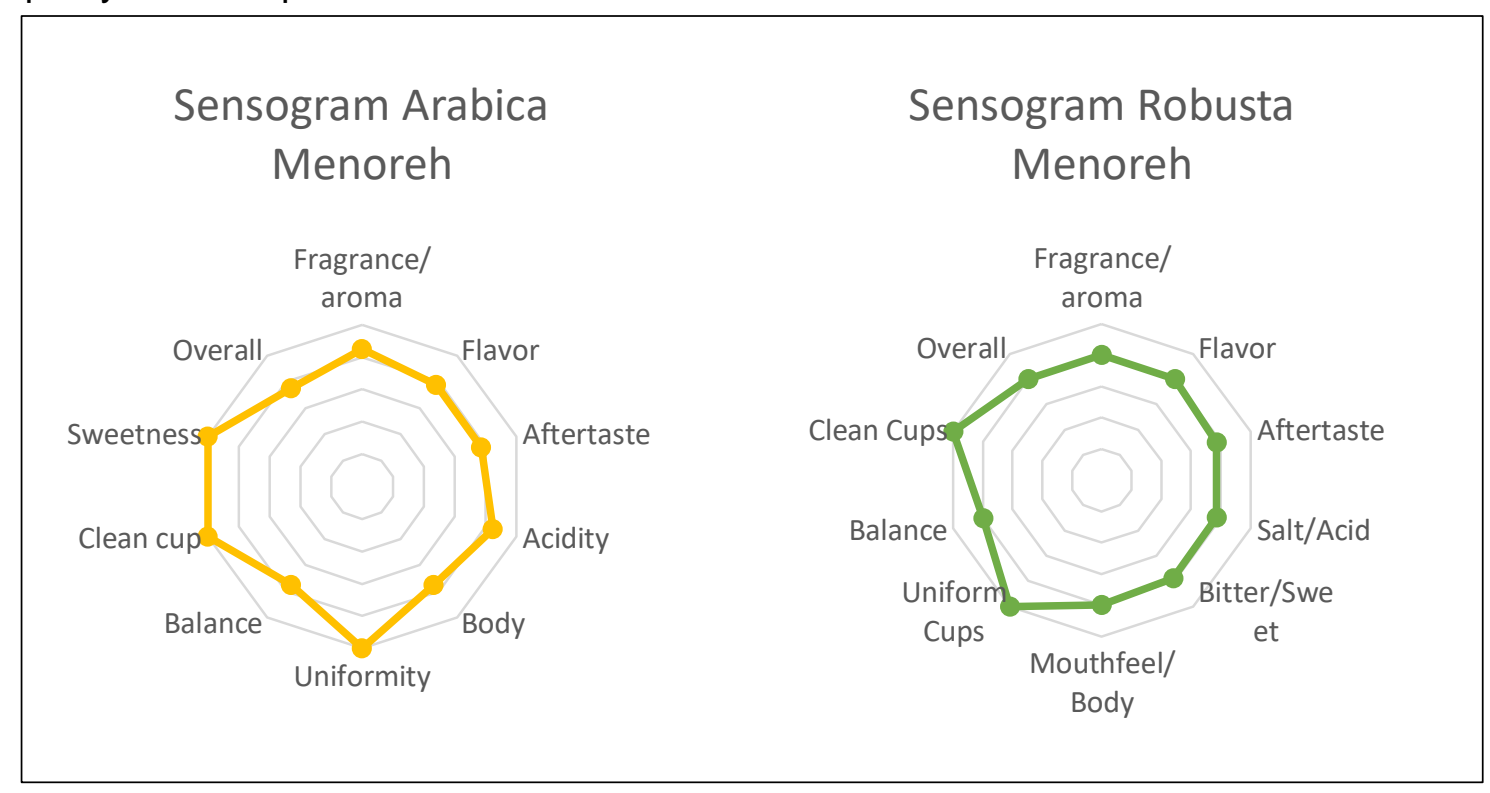

Gambar 3. Sensogram kopi arabika dan robusta Menoreh 
Berdasarkan uji cita rasa yang dilakukan, maka dapat dibuat sensogram yang digambarkan dengan diagram laba - laba. Sensogram tersebut ditunjukkan pada Gambar 3. Berdasarkan hasil uji cita rasa yang dilakukan, arabika Menoreh memperoleh nilai total sebesar 85,00 dimana nilai tertinggi terdapat pada atribut kualitas: (1) uniformity; (2) clean cup; dan (3) sweetness. Catatan dari panelis ahli terhadap cita rasa kopi arabika Menoreh adalah terdeteksinya cita rasa flowery, coffee blossom, vanilla dan bright acidity. Pada varian kopi robusta Menoreh, diperoleh nilai total sebesar 83,25 dimana nilai tertinggi terdapat pada atribut kualitas : (1) uniform cups; dan (2) clean cups. Catatan dari panelis ahli terhadap cita rasa kopi robusta Menoreh adalah terdeteksinya cita rasa chocolaty, vanilla dan daun pandan.

Melalui pengujian yang telah dilakukan terhadap varian kopi yang berasal dari Menoreh, Kulon Progo, Yogyakarta menunjukkan bahwa kopi tersebut sudah memenuhi standar kualitas secara nasional yang telah ditetapkan. Hal ini ditunjukkan pada hasil pengujian untuk parameter fisik, kimia, dan mikrobiologi dimana kualitas kopi bubuk yang berasal dari varian arabika dan robusta Menoreh telah memenuhi persyaratan tingkat I pada SNI 1-3542-2004. Pemenuhan terhadap syarat kualitas dalam suatu standar tersebut merupakan modal awal dan harus dipertahankan oleh produsen untuk dapat meningkatkan daya saing produk kopinya. Penerapan suatu standar dalam menjaga kualitas produk diperlukan sebagai bentuk inovasi dan pengembangan bisnis. Hal ini dikarenakan standardisasi dan penerapannya merupakan salah satu pilar penting dalam pengembangan daya saing perdagangan (Suminto, 2013). Aspek konsistensi kualitas menjadi hal yang harus dipelihara dengan baik oleh produsen kopi olahan dari kawasan Menoreh, Kulon Progo. Ketidakseragaman kualitas kopi dapat disebabkan oleh kurangnya pemahaman terhadap praktik proses pengolahan kopi baik di hulu maupun di hilir (Sudjarmoko, 2013). Penggunaan fasilitas pengolahan secara tersentral dapat membantu untuk mengurangi risiko dihasilkannya kualitas kopi yang tidak seragam (Arifin, 2010). Oleh karena itu, kelompok tani Madigondo bisa mengadopsi sistem pengolahan kopi tersentral dengan mengacu pada standar produksi yang telah berhasil menghasilkan kopi bubuk terstandar kualitas SNI.

Pengujian cita rasa yang telah dilakukan menunjukkan beberapa poin keunikan cita rasa dari kopi Menoreh, Kulon Progo. Cita rasa vanilla terdeteksi pada setiap varian kopi baik arabika maupun robusta. Ciri khusus pada varian arabika Menoreh adalah tingkat keasamaan ringan yang diwakilkan dengan kata "bright acidity", serta cita rasa natural atau bersifat alam yang diwakilkan dengan kata "flowery dan coffee blossom". Ciri khusus pada varian robusta Menoreh adalah rasa coklat yang teridentifikasi dengan kata "chocolaty". Kata - kata tersebut juga dapat berfungsi sebagai identifikasi cita rasa untuk kopi specialty karena mayoritas kata - kata tersebut sudah tercantum pada SCA Coffee Taster's Flavour Wheel.

Ada beberapa senyawa yang sudah terdeteksi sebagai senyawa prekursor cita rasa tertentu pada suatu jenis kopi specialty. Beberapa cita rasa kopi specialty yang telah dapat terdeteksi keberadaan senyawa volatil prekursornya adalah chocolaty, flowery, strawberry, caramel, hazelnut, dan fruity. (Laukaleja dan Kruma, 2018) Pada kopi Menoreh, kata - kata penggambaran cita rasa yang terdeteksi adalah cita rasa vanilla pada varian arabika dan robusta, cita rasa chocolaty pada varian robusta dan cita rasa flowery pada varian arabika.

Menurut Laukaleja dan Kruma, (2018), cita rasa chocolaty dan flowery disebabkan oleh kandungan senyawa volatil 3-methylbutanal dan linalool. 
Tingkat sangrai juga dapat mempengaruhi tingkat keberadaan senyawa volatil pada suatu kopi. Tingkat sangrai medium dapat memberikan stabilitas jumlah kandungan dan keberadaan senyawa volatil yang berperan sebagai senyawa prekursor cita rasa khas pada kopi spesialty (Laukaleja dan Kruma, 2018). Pada proses pengolahan hilir, telah dipilih tingkat sangrai medium sebagai acuan proses sangrai untuk varian arabika dan robusta sehingga dengan acuan tersebut dapat memunculkan cita rasa khas dari kopi Menoreh.

Kata-kata yang teridentifikasi oleh panelis ahli pada pengujian cita rasa tersebut dapat dijadikan sebagai kata kunci dalam proses promosi sehingga dapat meningkatkan brand image produk kopi olahan Menoreh seperti yang telah dikemukakan oleh (Sitanggang, 2013). Selain itu, nilai total cita rasa dari dua varian kopi Menoreh berada pada nilai di atas 80. Nilai arabika kopi Menoreh sebesar 85,00 menandakan bahwa varian kopi tersebut dapat dinyatakan sebagai specialty coffee pada level excellent. Nilai uji cita rasa yang berada di atas 80 merupakan indikator untuk penentuan jenis kopi specialty (SCAA, 2015). Pasar kopi specialty yang oleh beberapa sumber seperti Kustiari (2007), Sudjarmoko (2013), Aklimawati et al., (2014), Hutabarat (2004) dan Arifin (2010) disebutkan sebagai salah satu ceruk pasar yang dapat disasar oleh produsen kopi Indonesia. Berdasarkan nilai total uji cita rasanya, kopi arabika dan robusta Menoreh tersebut berpotensi untuk dapat dikembangkan dan bersaing di pasar kopi specialty baik di Indonesia maupun di dunia karena memiliki nilai total cita rasa di atas 80 .

\section{SIMPULAN}

Terdapat dua varian kopi yang tumbuh di kawasan Menoreh, Kulon Progo, Daerah Istimewa Yogyakarta, yaitu arabika dan robusta. Kedua varian tersebut sudah diolah menjadi kopi bubuk siap seduh. Berdasarkan hasil pengujian yang telah dilakukan maka hasil olahan produk kopi Menoreh sudah memenuhi persyaratan mutu tingkat I (pertama) untuk SNI 1-35422004 tentang bubuk kopi. Cita rasa utama yang terdeteksi pada varian arabika dan robusta Menoreh adalah cita rasa vanilla. Varian arabika dan robusta Menoreh juga berpotensi untuk dikembangkan menjadi kopi specialty asal Daerah Istimewa Yogyakarta. Pengembangan tersebut harus mempertimbangkan aspek pengendalian kualitas agar keseragaman kualitas berstandar SNI tetap dapat diperoleh serta aspek penguatan terhadap brand image dengan promosi yang didasarkan pada cita rasa khas kopi dari kawasan Menoreh, Kulon Progo, Daerah Istimewa Yogyakarta.

\section{UCAPAN TERIMA KASIH}

Penulis mengucapkan terima kasih atas dukungan keuangan untuk penelitian ini dari Bank Indonesia Kantor Perwakilan Yogyakarta yang berperan sebagai mitra kerjasama dalam proyek pengembangan kluster kopi Menoreh, Daerah Istimewa Yogyakarta.

\section{DAFTAR PUSTAKA}

1. Aklimawati, L., Yusianto, dan Mawardi, S. 2014. Karakteristik Mutu dan Agribisnis Kopi Robusta di Lereng Gunung Tambora, Sumbawa. Pelita Perkebunan. 30(2): 159 - 180. doi:10.21082/jtidp.v4n3.2017.p145-152.

2. Arifin, B. 2010. Global Sustainability Regulation and Coffee Supply Chains in Lampung Province, Indonesia. Asian Journal of Agriculture and Development. 7(2): $\quad 67 \quad-\quad 89$. doi:10.22004/ag.econ.199090.

3. Ariyanti, M., dan Suprapti. 2016. Cemaran Mikrobiologis Biji Kakao Asal Sulawesi Barat dan Tenggara dan Kaitannya dengan Keamanan Pangan. Standardisasi. 18(1): $52-60$. doi:10.31153/js.v18i1.697.

4. Badan Pusat Statistik. 2018. Statistik Daerah Kulon Progo 2018 (34010.1816). Kulon Progo: BPS Kabupaten Kulon Progo. Diakses dari 
https://Kulon

Progokab.bps.go.id/publication/.

5. Badan Standardisasi Nasional. 2004.Standar Nasional Indonesia Kopi Bubuk (SNI 1-3542-2004). Jakarta, DKI: BSN. Diakses dari http://sispk.bsn.go.id/SNI/DetailSNI/6674

6. Badan Standardisasi Nasional. 2009. Standar Nasional Indonesia Batas Maksimum Cemaran Logam Berat Dalam Pangan (SNI 7387:2009) Jakarta, DKI: BSN. Diakses dari http://sispk.bsn.go.id/SNI/DetailSNI/7772

7. Badan Standardisasi Nasional. 2013. Draft Strategi Standardisasi Nasional 2015 - 2025. Jakarta, DKI: BSN. Diakses dari https://bsn.go.id/uploads/download/........ .standardisasi_1.pdf.

8. Edvan, B. T., Edison, R., dan Same, M. 2016. Pengaruh Jenis dan Lama Penyangraian pada Mutu Kopi Robusta (Coffea robusta). Agroindustri Perkebunan. 4(1): 31 - 40. doi:10.25181/aip.v4i1.34.

9. Efanny, M. 2018. Kajian Paparan Logam Berat dari Pangan di Indonesia. Institut Pertanian Bogor, Bogor.

10. Food and Agriculture Organization. 2018. The State of Agricultural Commodity Markets 2018 Agricultural trade, climate change and food security. Rome: FAO. Diakses dari http://www.fao.org/.........i9542en.pdf.

11. Food and Agriculture Organization. 2019. Coffee Production Quantity World Data 2016 - 2017. Rome: FAO. Diakses dari

http://www.fao.org/faostat/en/?\#data/QC

12. Firmanto, H., Widyotomo,S., dan Suharyanto, E. 2018. Pengolahan Produk Hilir Kopi. Dalam Penangangan Pascapanen, Pengolahan, Alat Mesin dan Diversifikasi Limbah Kopi, diedit oleh Misnawi dan Widyotomo, S., 79113. Jember: Pusat Penelitian Kopi dan Kakao Indonesia.

13. Heidger, M. 2015. Ash (gravimetric, calculated from minerals, alkalinity of ash). Diakses dari https://www.institutheidger.de/ash-gravimetric-calculatedfrom-minerals-alkalinity-ofash/?lang=en.

14. Herrera, J. C., dan Lambot, C. 2017. The Coffee Tree-Genetic Diversity and
Origin. Dalam The Craft and Science of Coffee, diedit oleh Folmer, B., Blank, I., Farah, A., Giulino, P., Sanders, D., dan Wille, C., 1 - 16. UK: Elsevier.

15. Hutabarat, B. 2004. Kondisi Pasar Dunia dan Dampaknya Terhadap Kinerja Industri Perkopian Nasional. Agro Ekonomi. 22(2): 147 - 166. doi:10.21082/jae.v22n2.2004.147-166.

16. Kustiari, R. 2007. Perkembangan Pasar Kopi Duni dan Implikasinya Bagi Indonesia. Forum Penelitian Agro Ekonomi. $25(1)$ : 43 - 55. doi:10.21082/fae.v25n1.2007.43-55.

17. Lambot, C., Herrera, J. C., Bertrand, B., Sadeghian, S., Benavides, P., dan Gaitan, A. 2017. Cultivating Coffee Quality-Terroir and Agro-Ecosystem. Dalam The Craft and Science of Coffee, diedit oleh Folmer, B., Blank, I., Farah, A., Giulino, P., Sanders, D., dan Wille, C., 17 - 49. UK: Elsevier.

18. Laukaleja, I., dan Kruma, Z. 2018. Quality of Specialty Coffee: Balance Between Aroma, Flavour, and Biologically Active Compound Composition: Review. Research For Rural Development. 1: 240 - 247. doi:10.22616/rrd.24.2018.038.

19. Lingle, T. R., dan Menon, S. N. 2017. Cupping and Grading-Discovering Character and Quality. Dalam The Craft and Science of Coffee, diedit oleh Folmer, B., Blank, I., Farah, A., Giulino, P., Sanders, D., dan Wille, C., 181 203. UK: Elsevier.

20. Martoyo, P. Y., Hariyadi, R. D., dan Rahayu, W. P. 2014. Kajian Standar Cemaran Mikroba Dalam Pangan di Indonesia. Standardisasi. 16(2): 113 124. doi:10.31153/js.v16i2.173.

21. Pragita, T. E., Rahuyuningsih, M., dan Muslich. 2017. Evaluasi Penyimpangan dan Perbaikan Mutu Tempe Sesuai SNI 3144:2015 di UMKM.Standardisasi. 19(2): 113-126. doi:10.31153/js.v19i2.502.

22. Sanz-Uribe, J. R., Yusianto, Menon, S. N., Peneula, A., Oliveros, C., Husson, J., Brando, C., dan Rodriguez, A. 2017. Postharvest Processing-Revealing the Green Bean. Dalam TheCraft and Science of Coffee, diedit oleh Folmer, B., Blank, I., Farah, A., Giulino, P., Sanders, D., dan Wille, C., $245-271$. UK: Elsevier.

23. Sancho, M. T., Muniategui S., Sanchez, P., Huidobro, J. F., dan Simal-Lozano, J. 1992. Evaluating soluble and insoluable 
ash, alkalinity of soluble and insoluble ash and total alkalinity of ash in honey using electrical conductivity measurements at $20^{\circ}$ C. Apidologie. 23(4): 291-297. Diakses dari https://hal.archives-ouvertes.fr/

24. Sarirahayu, K. dan Aprianingsih, A. 2018. Strategy to Improving Smallholder Coffee Farmers Productivity. Asian Journal of Technology Management. 11(1):

$1-9$. doi:10.12695/ajtm.2018.11.1.1.

25. Specialty Coffee Association. 2019. The Coffee Taster's Flavor Wheel. Diakses dari https://sca.coffee/research/.

26. Specialty Coffee Association of America. 2015. SCAA Protocols Cupping Specialty Coffee. Diakses dari https://www.scaa.org/PDF/resources/cu pping-protocols.pdf.

27. Schenker, S., dan Rothgeb, T. 2017. The Roast-Creating The Beans' Signature. Dalam The Craft and Science of Coffee, diedit oleh Folmer, B., Blank, I., Farah, A., Giulino, P., Sanders, D., dan Wille, C., 245 - 271. UK: Elsevier.

28. Sitanggang, J. T. N., dan Sembiring, S. A. 2013. Pengembangan Potensi Kopi sebagai Komoditas Unggulan Kawasan Agropolitan Kabupaten Dairi. Ekonomi dan Keuangan. 1(6): 33-48. Diakses dari https://jurnal.usu.ac.id.

29. Sudjarmoko, B. 2013. Prospek Pengembangan Industrialisasi Kopi Indonesia. Sirkuler Inovasi Tanaman Industri Penyegar. 1(3): 99-110. Diakses dari http://balittri.litbang.pertanian.go.id.

30. Suminto, Kristiningrum, E., Widyatmoko, W., dan Susanto, D. A. 2013. Kesesuaian Mutu Produk Unggulan UKM Sektor Pangan terhadap Standar Nasional Indonesia. Standardisasi. 15(3): 212-229.
31. Suwarmini, N. N., Mulyani, S., dan Triani, I. G. A. L. 2017. Pengaruh blending kopi robusta dan arabika terhadap kualitas seduhan kopi. Rekayasa dan Manajemen Agroindustri. 5(3): 85-92. Diakses dari https://ojs.unud.ac.id/index.php/jtip/ar ticle/view/35502.

32. World Coffee Research. 2017. World Coffee Research Sensory Lexicon ver. 2 (A tool for understanding and measuring coffee's flavors and aromas). Diakses darihttps://worldcoffeeresearch.org/medi a/documents/20170622 WCR Sensory Lexicon 2-0.pdf

33. Widaningrum, Miskiyah, dan Suismono. 2007. Bahaya Kontaminasi Logam Berat dalam Sayuran dan Alternatif Pencegahan Cemarannya. Buletin Teknologi Pascapanen Pertanian. 3: 1627.

Diakses darihttp://ejurnal.litbang.pertanian.go.id.

34. Workman, D. 2019. Coffee Exports by Country. Diakses dari http://www.worldstopexports.com/coffeeexports-country/

35. Yusianto dan Widyotomo, S. 2018. Panen dan Pengolahan Produk Hulu Kopi. Dalam Penangangan Pascapanen, Pengolahan, Alat Mesin dan Diversifikasi Limbah Kopi,diedit oleh Misnawi dan Widyotomo, S., 1-78. Jember: Pusat Penelitian Kopi dan Kakao Indonesia. 